\title{
An integrated tool for the energy and seismic diagnosis and refurbishment of buildings at urban scale
}

\author{
Lorenzo Belussi ${ }^{1}$, Ludovico Danza ${ }^{1}$, Matteo Ghellere ${ }^{1}$, Giulia Guazzi ${ }^{1}$, Italo Meroni ${ }^{1}$, Francesco \\ Salamone ${ }^{1}$, Michele Palermo ${ }^{2}$, Tomaso Trombetti ${ }^{2}$, Sandra Deisvaldi $^{3}$, Paolo Piazza ${ }^{3}$ \\ ${ }^{1}$ ITC-CNR, San Giuliano Milanese, Italy \\ ${ }^{2}$ DICAM, School of Engineering and Architecture, University of Bologna, Bologna, Italy \\ ${ }^{3}$ ICIE, Bologna, Italy
}

\begin{abstract}
Modelling of the behaviour of the complex flows that characterize the urban fabric is a hot topic for the definition of future sustainable policies. The article presents a method based on a synergic and integrated bottom-up approach for both energy efficiency and seismic analysis for the refurbishment of buildings at urban scale. The method can be applied to the entire urban fabric without distinction of the intended use of buildings, representing a transition toward an organic urban planning and management. The model is applied to a district of Bologna in order to identify the most suitable integrated refurbishment scenarios.
\end{abstract}

\section{Introduction}

The urban environment is the field where the researches, policies and interests of different stakeholders converge in order to develop action plans for a sustainable urbanization. The widespread knowledge of the characteristics of the building stock is crucial to reach this goal (Hamilton et al., 2005). Buildings have significant impacts on different fields. From the energy point of view, they account for about $40 \%$ of global consumption and $30 \%$ of global $\mathrm{CO}_{2}$ emissions, having a relevant role in the climate change (Belussi et al., 2019). Buildings contribute to human safety in case of natural events such as earthquakes or other natural hazards. Due to these complexities, urban policies have to consider several characteristics related to buildings and the built environment in order to provide the most suitable solutions following a holistic approach.

The state-of-the-art of building retrofit and enhancement interventions provides a fragmented approach according to which every aspect is treated separately without a common direction and target (Calvi et al., 2016). This trend is favoured by a legislation drawn up in accordance with the same principle. The recent European Directive on energy performance of buildings is scattering this common rule by coupling the building energy and environmental performance with the related seismic risk, all with a view to economic feasibility. However, many challenges need to be addressed and overcome to make this paradigm a reality, making our cities more sustainable (La Greca and Margani, 2018).

As it often happens, the world of research has been ahead of its time by proposing some cases of integrated approach for the refurbishment of buildings.
In general, the current state-of-the-art reports case-bycase analyses where the interventions are fitted to the peculiarities of the building. Marini et al. (2017) describe a holistic proof of concept for a deep renovation of an existing Reinforced Concrete (RC) residential building. The authors highlight the potential benefits of a typical structural intervention, the self-supporting exoskeleton, coupled with an energy design to improve the resilience, the energy performance and the environmental impact of the building. Similarly, in Manfredi and Masi (2018) the authors investigate the role of masonry infill walls on the thermal and seismic performance of a RC building in different configurations. In Simona et al. (2017) the authors demonstrate how the integrated rehabilitation of the infill elements provides an additional strength to the building meeting the requirements of low and medium seismic risk zones. In high seismic risk zones an additional intervention on the RC frames is required. In Basiricò and Enea (2018) the subjects of the investigation are historic masonry buildings. Walls and roofs undergo a deep energy and seismic retrofitting/refurbishment, paying attention to the economic feasibility of the intervention.

A current field of research of the building engineering sector is focused on the analysis of the performance of the urban fabric as a complex set of buildings that interact with each other and with the built environment, including connecting areas. The aim of these researches is to better understand the areas and buildings with the highest impact and the future effects of renovation scenarios. The outcomes are methods and tools in support of public administration for the definition of the most suitable action policy plans.

Following this path, the paper presents an integrated approach based on energy and seismic analyses of the built environment aimed at detecting the suitable "costeffective" measures for the refurbishment of buildings at urban scale. The approach is integrated into a web tool designed as a support for the energy and seismic planning of urban areas where the final potential users are the public administrations and the stakeholders involved in this field. The paper describes the methodological approach, the preliminary results of the research activity and the potentials of the overall system. In particular, the actual results refer to the diagnosis of buildings at urban scale. A common building taxonomy between the energy and seismic model has been 
developed in order to classify the buildings in an unambiguous way. The energy and the seismic diagnoses have been developed separately according to a bottom-up approach. Integrated refurbishment scenarios have been defined detecting the optimisation possibilities provided by the two combined approaches. The overall methodology is transferred into a web tool aimed at collecting and managing all available information for the energy and seismic diagnosis, producing thematic maps and providing refurbishment scenarios. The data related to each individual building and the integrated results of the diagnoses and refurbishment interventions are aggregated at district level through a GIS tool so that a number of thematic maps can be produced dealing with energy performances and seismic risk-related exposures. The reliability of the system is tested on a real urban district located in Bologna.

\section{Methods}

The proposed bottom-up methodology (for mapping the energy and seismic behaviour of buildings at urban scale and for detecting the most suitable integrated renovation scenarios) is based on the analysis of a variety of information, including those already provided by opensource database needed to characterize the building stock from a geometrical, morphological, energy and seismic point of view.

The methodology consists of three levels of analysis:

- level I: fast assessment,

- level II: standard assessment,

- level III: deep assessment.

The level of assessment may vary for each project depending on the type and extent of surveys (e.g. using only web-based tools such as Google Street View, coupling with in-situ reconnaissance campaign, carrying out detailed surveys including inspections inside the buildings,...) and availability of further data and information (design plans, consumptions, ...). In the current paper, attention is drawn to the results of level I that allows a preliminary analysis of the energy and seismic performance of urban fabric based on fast surveys. The scheme of the proposed methodology is presented in Figure 1 and described in the following paragraph.

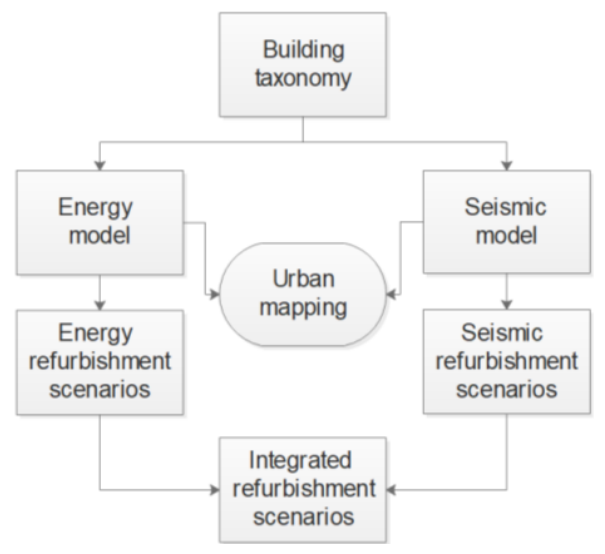

Figure 1: Process scheme.
The twofold (energy and seismic) bottom-up approach starts from an integrated definition of the energy and seismic characteristics of buildings, based on an extended taxonomy, defined to integrate the two fields of analysis. In this way, the geometrical, morphological and technical characteristics of each building are uniquely identified and these data can be used for the following energy and seismic analysis, according to the specific procedures defined for the two models. In the diagnosis phase, in the strict sense, the models work independently in order to identify the buildings deficiencies from the energy and seismic point of view. Refurbishment is the field which brings together the energy and seismic approach. In this phase, integrated solutions are proposed as a function of the buildings characteristics.

\section{Building taxonomy}

The aim of the building taxonomy is to classify buildings in a uniform manner. The process is widely used in seismic engineering as a key step towards assessing the seismic risk of a building (Hancilar et al., 2013). For seismic risk assessment at urban-scale, a fragility and/or vulnerability model is usually assigned to individual buildings through risk-oriented taxonomies. In Europe, the European Macroseismic Scale (Grünthal, 1998) has been used in several countries for risk assessment purposes (Tyagunov et al., 2004; Lagomarsino and Giovinazzi, 2006; Schwarz et al., 2006; Bernardini et al., 2010). The EMS-98 scale introduces 15 classes of buildings, mainly accounting for wall materials and different levels of seismic design. Each building class is paired with a level of seismic vulnerability ranging from "A" (most vulnerable) to "F" (less vulnerable). The HAZUS taxonomy (Kircher et al., 2006) has been extensively employed to model building inventories in America (Aguirre et al., 2018). The global exposure model proposed within the 2013 Global Assessment Report (GAR) employed the PAGER-STR taxonomy (Jaiswal et al., 2010) to encode building types (De Bono and Mora, 2014). A comprehensive faceted taxonomy has been introduced within the Global Earthquake Model (GEM) activities to provide a more standardized building description and classification for seismic risk assessment. A so-called "faceted taxonomy" is a more flexible approach consisting of a set of taxonomies, each of them describing a particular aspect or facet of the building seismic vulnerability. Faceted taxonomies have several advantages over a single hierarchy of attributes in terms of clarity, compactness, expandability. More in detail, the GEM building taxonomy v2.0 makes use of 13 attributes (see Figure 2).

Each attribute corresponds to a specific building characteristic that affects its seismic performance. Typical attributes include material, lateral load-resisting system, building height, etc. The proposed taxonomy scheme is flexible and provides an opportunity for adding and/or modifying attributes depending upon the level of detail required and the new knowledge gained through the data collection process. In building engineering the interest in this branch has grown in step with the interest in the analysis of the energy 
performance of large existing building stocks (Dascalaki et al., 2010).

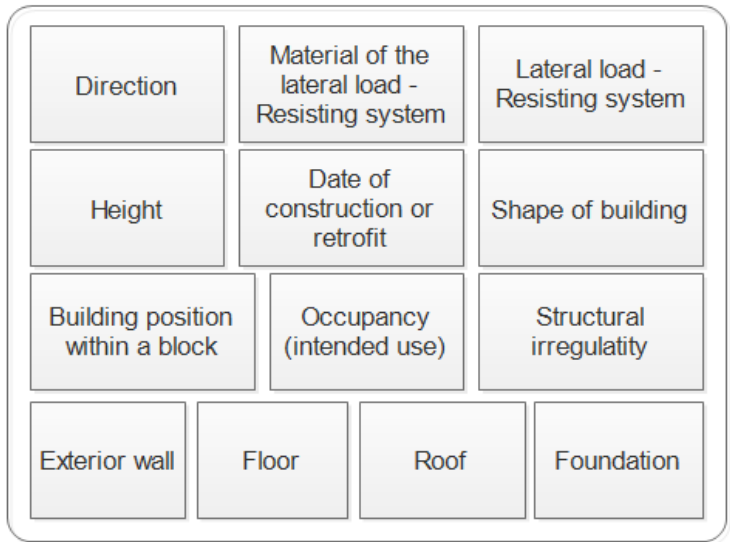

Figure 2: GEM Building taxonomy attributes.

Following one of the most referenced researches on this topic, the TABULA project (Ballarini et al., 2014) and other studies (Manta et al., 2016), the main attributes to uniquely identify a building typology are defined and summarized in Figure 3.

\begin{tabular}{|c|c|c|c|}
\hline Weather data & Intended use & \multicolumn{2}{|c|}{$\begin{array}{c}\text { Date of construction } \\
\text { or retrofit }\end{array}$} \\
\hline $\begin{array}{l}\text { Surface to volume } \\
\text { ratio }(\mathrm{S} / \mathrm{V})\end{array}$ & \multicolumn{2}{|c|}{$\begin{array}{c}\text { Net floor area } \\
\text { per thermal zone }\end{array}$} & $\begin{array}{l}\text { Number of } \\
\text { thermal zone }\end{array}$ \\
\hline Wall & Floor & & Window \\
\hline $\begin{array}{l}\text { Heating ventilation } \\
\text { and air conditioning } \\
\text { (HVAC) data }\end{array}$ & \multicolumn{2}{|c|}{$\begin{array}{c}\text { Domestic hot } \\
\text { water }(\mathrm{DHW}) \text { data }\end{array}$} & $\begin{array}{l}\text { Lighting and } \\
\text { equipment } \\
\text { data }\end{array}$ \\
\hline
\end{tabular}

Figure 3: Attributes for energy assessment of buildings.

The building taxonomy developed within the research activity belongs to the categories of faceted taxonomies since it is developed in order to include the main attributes affecting both the seismic and energy performance of buildings. The integrated taxonomy is organized through a series of multidimensional tables, each of them collecting a number of information pertaining to several attributes. The information collected in the tables are then used to associate each building with a specific energy performance and a seismic vulnerability class. The number and size of each table depend on the level of investigation (level I, level II and level III).

\section{Energy model}

The energy model is based on the bottom-up framework proposed in Belussi et al. (2017) for mapping the energy consumption of buildings and on a multiple linear regression analysis (Fichera et al., 2016) for the definition of the most suitable refurbishment scenarios.

The model is developed starting from the analysis of the available information provided by open-source databases needed to characterize the building stock from a geometrical, morphological and functional point of view. The core of the energy model is the Reference Buildings Matrix (RBM) (Corgnati et al., 2013) defined by combining the information derived from existing databases about: intended use, period of construction, building shape factor, following the path of the current scientific literature (Reinhart and Davila, 2016). The system considers both residential and non-residential reference buildings. The energy indexes related to the thermal or primary energy are expressed in $\mathrm{kWh} / \mathrm{m}^{2} \mathrm{y}$, for both intended uses, as required by the current legislation. The RBM consists of 80 basic reference buildings. The RBM is built using information derived from the TABULA building typology database for residential buildings (Loga et al., 2016) and the register of Energy Performance Certificates (EPC) for nonresidential ones ( $\mathrm{Li}$ et al., 2015). The data from TABULA are assumed in standard conditions (Belussi et al., 2018) in order to guarantee the homogeneity with the information from the EPCs. For non-residential buildings the data from EPCs are statistically analysed to define specific reference buildings for each intended use. In the RBM, the buildings are classified in 7 categories according to their intended use: residential, manufacturing, recreational/cultural, school, health, commercial, office. As far as residential buildings are concerned, 4 subcategories are further considered as a function of the shape factor: single family house, terraced house, multifamily house, apartment block. Concerning the period of construction, 8 ranges are considered: before 1900, from 1900 to 1919 , from 1919 to 1945 , from 1945 to 1960 , from 1960 to 1975 , from 1975 to 1991, from 1991 to 2005, after 2005. The outputs of the RBM are the thermo-energy indices characterizing the building behaviour: energy needs for heating and Domestic Hot Water (DHW); heating and global primary energy; average thermal transmittance of walls, roofs, basements and windows; annual efficiency factor for heating, DHW and as a whole; $\mathrm{CO}_{2}$ emissions. Future development of the system will consider further energy indicators such as those related to cooling.

The indices of the RBM are assigned to each real building according to the intended use, period of construction and shape factor in order to analyse the energy performance of the urban fabric. To reach this target, each building of the urban fabric has to be characterized using the available databases. For the current research, the following sources were considered. The morphological and geometrical data are derived from the Geographic Information System, available at each Italian public administration that allows the management of cartographic data and geo-referenced spatial information. More in detail, the information derived from this source refers to the data necessary to identify a building in terms of physical boundaries, dimension (surface and volume) and intended use. The Municipal Base Map identifies the shape of each building providing geometrical information such as building height, volume and plan dimensions. The Town Development Plan collects information about the 
prevailing intended use of buildings. Finally, the use of urban Census data allows the identification of the period of construction. This source provides information about census sections corresponding in most cases to a block or a part of buildings. A frequency analysis allowed to determine the construction period of all the buildings belonging to the census section. At the end of this process, each building is uniquely characterized and may be associated with the respective category of the RBM for the assessment of energy behaviour at urban level. The described procedure has the advantage of being adaptable and replicable in several contexts, due to the availability of open-source data. Nevertheless, the overall energy assessment appears still raw because of the reliability of the input data. To overcome this limit, the system provides the possibility to define the characteristics of the buildings through remote or in-field surveys. The refurbishment model is based on a multiple linear regression whose dependant variables, $\mathrm{Y}_{\mathrm{i}}$, describe the energy behaviour of the building (heating and global primary energy and $\mathrm{CO}_{2}$ emissions) and regressors, $X_{j}$, are the thermo-physical properties of buildings. The parameters $\beta_{i, j}$ of each equation are estimated from the TABULA building typology database and the register of EPCs. The effect of renewable energy sources is computed through a coverage ratio of the global primary energy.

\section{Seismic model}

The seismic risk module focuses on the assessment of seismic risk of buildings at regional scale. The risk is evaluated combining (e.g. integrating) the hazard curve $\mathrm{H}$, the vulnerability curve $\mathrm{V}$ and an exposure curve $\mathrm{E}_{\mathrm{i}}$ according to the well-known seismic risk assessment framework (see Figure 4):

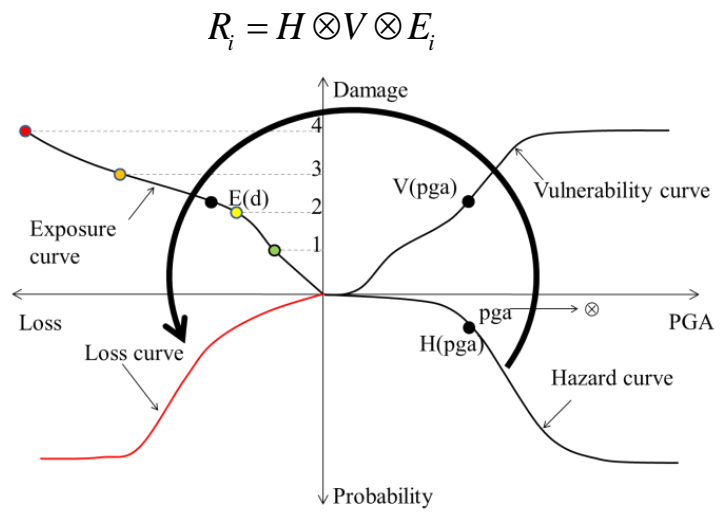

Figure 4: Seismic Risk framework.

In equation (1), the hazard curve $\mathrm{H}$ is the cumulative distribution function of the selected intensity measure and is specific to the site of interest. It is common to use the peak ground acceleration (PGA) as intensity measure $\mathrm{H}$ curves are typically obtained through probabilistic seismic hazard analyses (PSHA). For instance, $\mathrm{H}$ (PGA=pga) provides the probability that the PGA will be less or equal to pga in a given period of observation, which can differ based on the building's importance. The vulnerability curve $\mathrm{V}$ gives the value of the damage variable corresponding to a given value of PGA and can be obtained by combining the fragility curves related to each damage (limit state) level (GEM technical report Rossetto et al., 2015). In this study, the damage variable $\mathrm{V}$ takes on a value between 0 and 4 . In particular: $\mathrm{V}<1.0$ indicates the absence of damage; $V=1.0$ indicates the achievement of the Fully Operational limit state. $V=2.0$ indicates the achievement of Operational limit states. $\mathrm{V}=3.0$ indicates the achievement of Life Safety limit states; V=4 indicates the achievement of Near Collapse limit state. The exposure curves depend on the damage variable $\mathrm{V}$ and quantify the expected losses given a particular level of damage. The ensemble of the $E_{i}$ exposure curve $(\mathrm{i}=1, \ldots, \mathrm{N}$ indicating the different exposures) quantifies the possible consequences corresponding to a given damage level in terms of economic losses due to structural and non-structural damage, down-time, causalities. Symbol $\otimes$ indicates the integral of the product along the PGA axis. Risk curves have been grouped into the following categories: (1) losses due to damage to structural and non-structural components; (2) losses related to down-time; (3) losses due to causalities.

The seismic retrofitting interventions are first categorized into five classes based on the expected improvement of the seismic capacity. Classes I and II include ordinary maintenance interventions and the elimination of punctual elements that are critical in a high risk earthquake scenario such as slender chimneys, short columns,... Class III includes interventions of seismic improvement leading to a target increase in the seismic capacity. Classes IV and V include interventions of seismic improvement up to $60 \%$ of the $100 \%$ capacity of a new construction. For each intervention class, a catalogue of interventions is provided together with information regarding cost, compatibility and effectiveness with respect to different structural configurations and typologies.

\section{Urban model and mapping}

The main results and considerations of the analyses carried out at the building level and at urban scale (relating, for example, to road and network analysis, such as travel times to reach buildings of considerable interest), respectively, are dealt with at urban level by introducing the concept of Urban Minimum Area (UMA), i.e. the "place" of the representation of the characteristic parameters of the district scale.

The analysis at urban scale provides different results (e.g. people exposure, physical exposure, functional exposure, direct vulnerability, additional vulnerability, local vulnerability, vulnerability by specialization, global primary energy, $\mathrm{CO}_{2}$ emissions, gas/electric energy/water consumption); these values can be aggregated at the level of UMA or can be representative of the systems in the UMA itself (residential, manufacturing, commercial, recreational/cultural, educational, sanitary, services, public property).

\section{Refurbishment scenarios}

The energy and seismic diagnoses provide an overview of the current state of the buildings of the selected urban 
area, each for its own field of interest. Refurbishment is the field which brings together the energy and seismic approach. This section consists of 3 main steps:

1. Definition of the repertoire of refurbishment interventions.

2. Definition of the allocation matrix.

3. Choice of compatible interventions

The repertoire is designed as an implementable repository where a series of refurbishment interventions are collected. The system architecture allows to select either individual interventions for energy only or seismic improvements only or packages with integrated interventions coupling energetic and seismic improvements.

The initial configuration provides the most common interventions for the improvement of the energy and seismic behaviour of buildings, such as: thermal insulation, high-performance windows, renewable energy sources systems, etc. The unit cost for each technical solution is also required to provide a cost/benefit analysis.

The allocation matrix is the core of this section and the element linking the energy and seismic evaluation together. Specific criteria identify a set of common features aimed at guiding the choice of the suitable technical solution. Following this approach, only the interventions that are compatible with the characteristics of the selected building are proposed for the refurbishment scenario.

For each selected building, a series of refurbishment solutions are proposed, each with its own cost, calculated by multiplying the unit cost by the reference variable.

Once buildings that need refurbishment interventions are defined, the tool provides for each building a set of technical solutions and the related achievable energy and seismic performance. The solution are filtered according to the previous results and those suitable to improve both energy and seismic behaviour combined (for example exoskeleton with thermal insulation). In this way the additional costs (for example, scaffolding or other equipment) are computed once. The final step is the choice of the most suitable technical solution or a combination of them. Currently the last procedure is made manually by the user; future development will provide an automatic optimization procedure.

\section{Case study}

The model has been applied to the district of Bolognina, located north of the municipal area of Bologna. The district consists of 580 buildings with different intended uses, 91 of which are garages or porches, that are elements of interest for the seismic analysis. $70 \%$ of them are buildings intended for single use, among which the residential use is the largest category, as shown in Figure 5. The term "multi-use" refers to buildings with different intended uses between the ground floor and the other floors or buildings where there are different intended uses within the same floors. This category mainly includes buildings with commercial activity at street level and residential units in the upper floors. Buildings within the considered district area were mainly built in the period $1920 \div 1975$, as shown in Figure 6, which implies that the construction types are mainly "Masonry" and "Reinforced concrete" (see Figure 7).

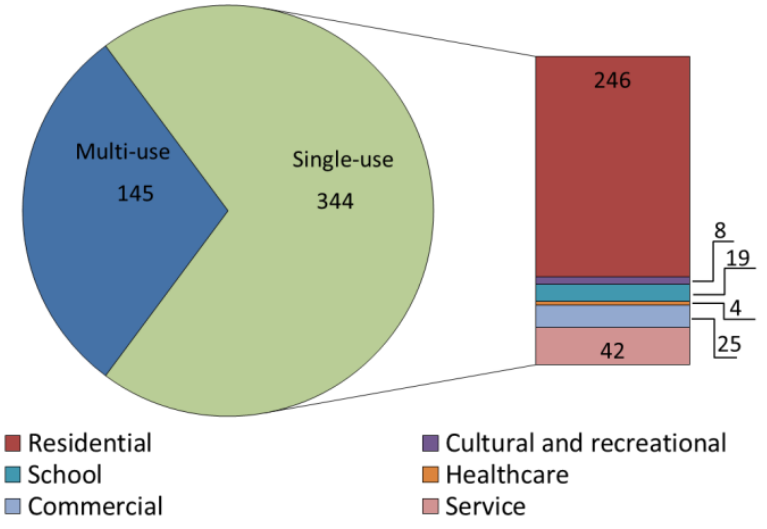

Figure 5: Intended uses of buildings in the district area.

Less than $5 \%$ of the buildings were built in recent years, when Italy had legislative guidelines in place for energy and seismic design. From the energy point of view, the values of mean thermal transmittance for walls and windows of the building envelope are about $1.30 \mathrm{~W} / \mathrm{m}^{2} \mathrm{~K}$ and $4.90 \mathrm{~W} / \mathrm{m}^{2} \mathrm{~K}$, respectively, and the heating plant mean global seasonal efficiency is about 0.60 .

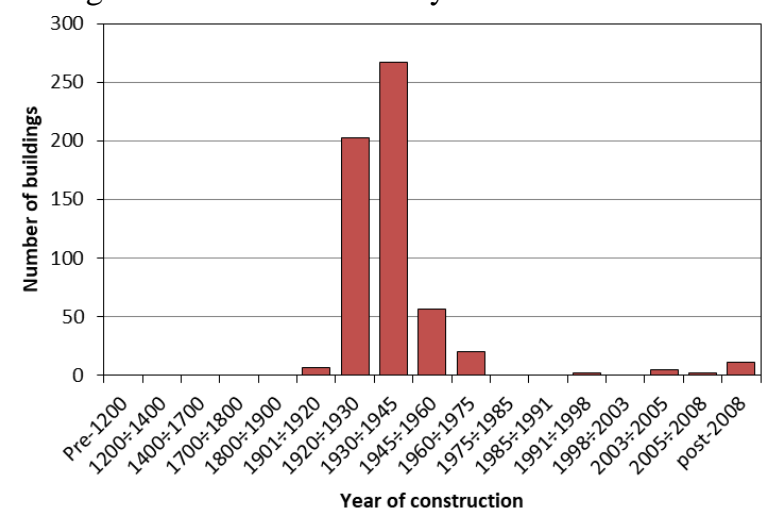

Figure 6: Year of construction of the buildings in the district area.

Further information from the available sources or infield surveys allow to define the geometry and morphology of each building for the following energy and seismic analyses.

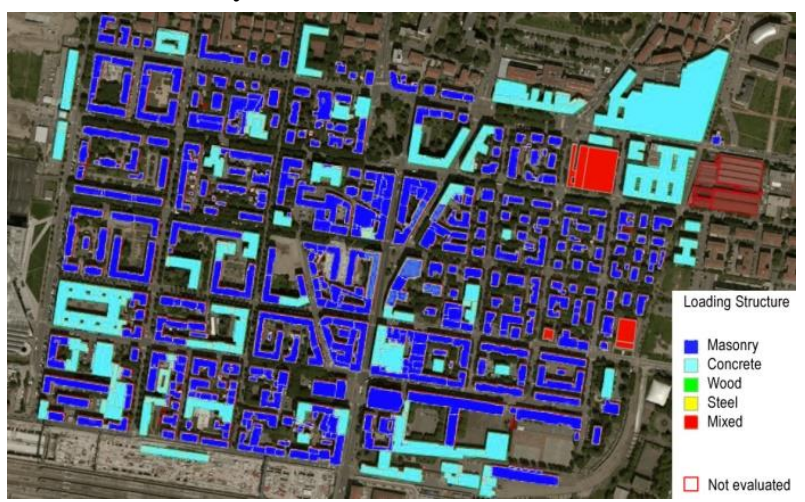

Figure 7: Construction type of buildings. 


\section{Results}

The application of the model allows the mapping of the energy and seismic performance of buildings inside the selected area. It must be underlined that, up to now, the initial analyses (see figures below), have been conducted according to assessment level I using web-based information only. As such, the results of the diagnosis are to be considered as preliminary results with large uncertainties since in-situ inspections are of fundamental importance for a more reliable seismic risk assessment. Nevertheless, the analyses provide examples of the capabilities and potentialities of the tool.

The distribution of the overall performance of buildings in terms of global specific primary energy, expressed in $\mathrm{kWh} / \mathrm{m}^{2} \mathrm{y}$, is shown in Figure 8.

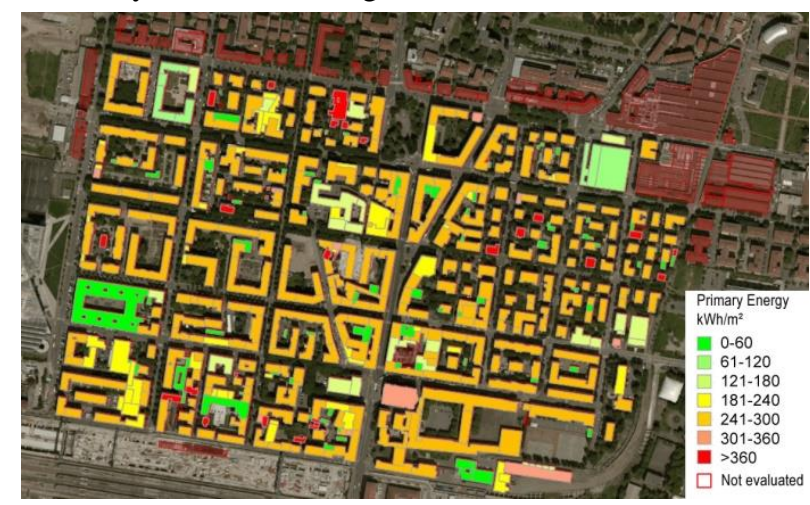

Figure 8: Global primary energy $\left(\mathrm{kWh} / \mathrm{m}^{2} \mathrm{y}\right)$.

Most of the buildings, about $70 \%$, show a primary energy in the range of $240-300 \mathrm{kWh} / \mathrm{m}^{2} \mathrm{y}$, corresponding approximately to energy classes $F$ and $G$ (the legend does not reflect the limits of the Italian energy certification). Less than $5 \%$ of the buildings show global primary energy lower than $120 \mathrm{kWh} / \mathrm{m}^{2} \mathrm{y}$.

The tool allows to estimate the total $\mathrm{CO}_{2}$ emissions for each building. Figure 9 shows the distribution over the area of the district.

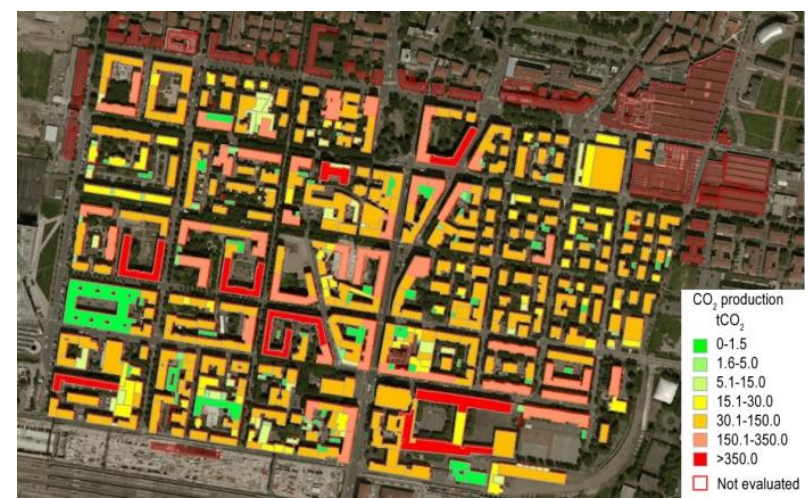

Figure 9: $\mathrm{CO}_{2}$ emissions ( $\mathrm{t} \mathrm{CO}_{2}$ ) of buildings.

Selected seismic performances are shown through thematic maps in figures 10-14. For each building, the thematic maps show the characteristic value of the corresponding risk curve that is a given percentile of the curve (the 95 percentile in this case). Figures 10 and 11 provide exemplifying information on structural damage: the damage variable (Figure 10) and the index of seismic strength (Figure 11; note that the seismic strength classes range from $\mathrm{A}+$ to $\mathrm{F}$ according to the classification given by "Guidelines for the seismic risk classification of constructions" - Sismabonus). Figures 12, 13 and 14 provide information on the expected causalities, the extent of building failures and people exposure.

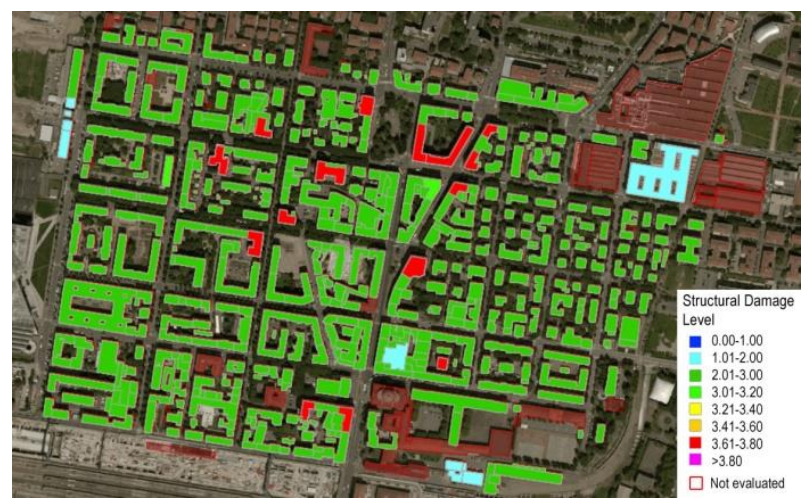

Figure 10: Structural damage level.

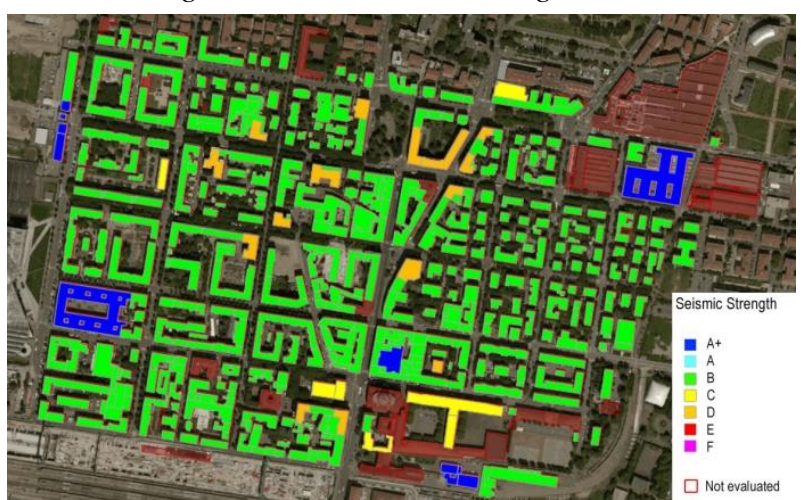

Figure 11: Index of seismic strength.

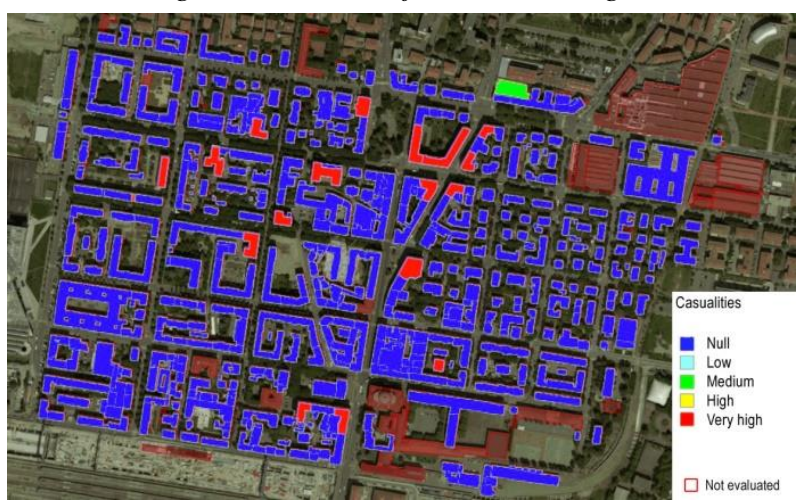

Figure 12: Casualties.

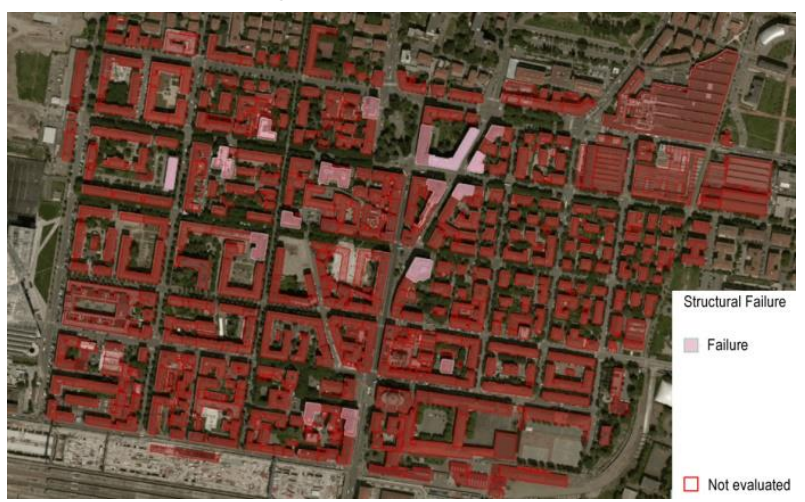

Figure 13: Extent of structural failure. 


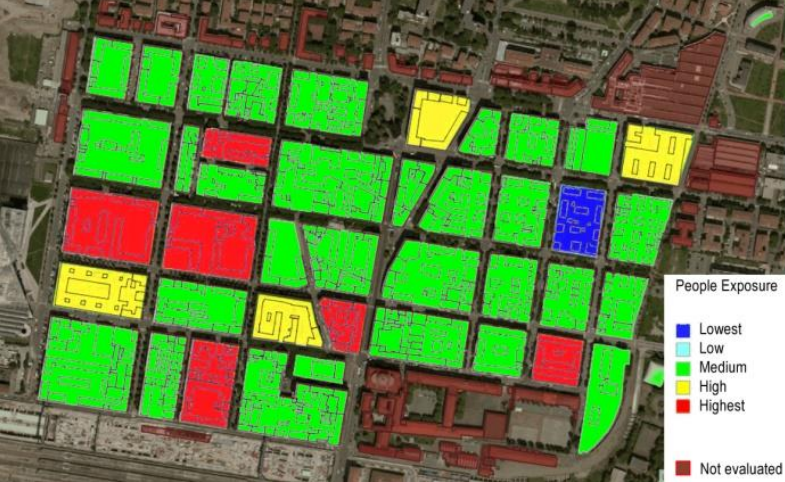

Figure 14: People exposure.

The integration of the energy and seismic diagnoses within the same tool allows to analyse the complex behavior of buildings at urban scale identifying the areas that may need refurbishment interventions. As described in the paragraph "Methods" the tool proposes to the user a series of compatible solutions based on the results of the diagnoses. In this way it is possible to define a hierarchy of interventions that is a very useful feature where the availability of resources requires a working schedule (which can be identified based on the real need for intervention).

\section{Conclusions}

The article describes an integrated multi-level methodology for the assessment of energy and seismic performance of buildings at urban scale on the basis of a bottom-up approach. The aim of the model is to provide the different stakeholders with a tool intended to support urban policies, identifying energy intensive and seismic risk areas providing useful refurbishment solutions from an overall performance point of view and a costeffectiveness assessment of such solutions.

The methodological approach is integrated into a web tool and the preliminary results are verified in a district of Bologna. The current state of the tool allows a deep characterization of the urban fabric with several information about the state of the buildings and their energy and seismic performance. The preliminary results are obtained from a knowledge of the urban fabric based on fast surveys, according to the lower level of analysis, based on public database and fast surveys.

Future developments will provide an in-depth investigation of the buildings characteristics based on on-site monitoring and surveys in order to guide the decision-making process towards efficient and effective interventions, according to the level II and III provide by the multilevel methodology. Furthermore, an optimization procedure will be defined in order to facilitate the user in choosing the best technical solutions for the building refurbishment.

\section{Acknowledgments}

The work described in the current paper is a partial result of the project RIGERS - Rigenerazione della città: edifici e reti intelligenti (project number SCN00040), supported by the National Operational Programme of Italy - Smart Cities and Communities.

\section{References}

Aguirre, P., Våsquez, J., de la Llera, J. C., Gonzålez, J., and Gonzålez, G. (2018). Earthquake damage assessment for deterministic scenarios in Iquique, Chile. Natural Hazards, 92, 1433-1461.

Ballarini, I., Corgnati, S. P., and Corrado, V. (2014). Use of reference buildings to assess the energy saving potentials of the residential building stock: The experience of TABULA project. Energy policy, 68, 273-284.

Basiricò, T., and Enea, D. (2018). Seismic and Energy Retrofit of the Historic Urban Fabric of Enna (Italy). Sustainability, 10(4), 1138.

Belussi, L., Barozzi, B., Bellazzi, A., Danza, L., Devitofrancesco, A., Fanciulli, C., Ghellere, M., Guazzi, G., Meroni, I., Salamone, F., Scamoni, F., Scrosati, C. (2019). A review of performance of zero energy buildings and energy efficiency solutions. Journal of Building Engineering, 25.

Belussi, L., Danza, L., Ghellere, M., Guazzi, G., Meroni, I., and Salamone, F. (2017). Estimation of building energy performance for local energy policy at urban scale. Energy Procedia, 122, 98-103.

Belussi, L., Danza, L., Meroni, I., Salamone, F., Minutoli, S., and Romeo, C. (2018). Simplified tool for the energy performance assessment of residential buildings. Modelling, Measurement and Control B, 87(3), 122-128.

Bernardini, A., Lagomarsino, S., Mannella, A., Martinelli, A., Milano, L., and Parodi, S. (2010). Forecasting seismic damage scenarios of residential buildings from rough inventories: a case-study in the Abruzzo Region (Italy). Proceedings of the Institution of Mechanical Engineers, Part O: Journal of Risk and Reliability, 224(4), 279-296.

Calvi, G. M., Sousa, L., and Ruggeri, C. (2016). Energy efficiency and seismic resilience: A common approach. In Gardoni, P., LaFave J. M., Multi-hazard Approaches to Civil Infrastructure Engineering. Springer, Cham.

Corgnati, S. P., Fabrizio, E., Filippi, M., \& Monetti, V. (2013). Reference buildings for cost optimal analysis: Method of definition and application. Applied energy, 102, 983-993.

Dascalaki, E. G., Droutsa, K., Gaglia, A. G., Kontoyiannidis, S., and Balaras, C. A. (2010). Data collection and analysis of the building stock and its energy performance-An example for Hellenic buildings. Energy and Buildings, 42(8), 1231-1237.

De Bono, A., and Mora, M. G. (2014). A global exposure model for disaster risk assessment. International journal of disaster risk reduction, 10, 442-451. 
D’Urso, M.G., Masi, D., Zuccaro, G., and De Gregorio, D. (2018) Multicriteria Fuzzy Analysis for a GISBased Management of Earthquake Scenarios. Computer-Aided Civil and Infrastructure Engineering, 33(2), 165-179.

Fichera, A., Inturri, G., La Greca, P., and Palermo, V. (2016). A model for mapping the energy consumption of buildings, transport and outdoor lighting of neighbourhoods. Cities, 55, 49-60.

Grünthal, G. (1998). European macroseismic scale 1998. European Seismological Commission (ESC), Luxemburg.

Hamilton, A., Wang, H., Tanyer, A. M., Arayici, Y., Zhang, X., and Song, Y. (2005). Urban information model for city planning. Journal of Information Technology in Construction, 10(6), 55-67.

Hancilar, U., Taucer, F., \& Tsionis, G. (2013). Guidelines for typology definition of European physical assets for earthquake risk assessment. SYNER-G Reference Report, 2.

Jaiswal, K., Wald, D., \& Porter, K. (2010). A global building inventory for earthquake loss estimation and risk management. Earthquake Spectra, 26(3), 731748.

Kircher, C. A., Whitman, R. V., \& Holmes, W. T. (2006). HAZUS earthquake loss estimation methods. Natural Hazards Review, 7(2), 45-59.

La Greca, P., and Margani, G. (2018). Seismic and energy renovation measures for sustainable cities: A critical analysis of the Italian scenario. Sustainability, 10(1), 254.

Lagomarsino, S., \& Giovinazzi, S. (2006). Macroseismic and mechanical models for the vulnerability and damage assessment of current buildings. Bulletin of Earthquake Engineering, 4(4), 415-443.

Li, Q., Quan, S. J., Augenbroe, G., Yang, P. P. J., and Brown, J. (2015). Building energy modelling at urban scale: Integration of reduced order energy model with geographical information. Proceedings of BS2015: 14th Conference of International Building Performance Simulation Association. Hyderabad, (India), 7-9 December , 2015.

Loga, T., Stein, B., and Diefenbach, N. (2016). TABULA building typologies in 20 European
countries-Making energy-related features of residential building stocks comparable. Energy and Buildings, 132, 4-12.

Manfredi, V., and Masi, A. (2018). Seismic Strengthening and Energy Efficiency: Towards an Integrated Approach for the Rehabilitation of Existing RC Buildings. Buildings, 8(3), 36.

Mantha, B. R., Menassa, C. C., \& Kamat, V. R. (2016). A taxonomy of data types and data collection methods for building energy monitoring and performance simulation. Advances in Building Energy Research, 10(2), 263-293.

Marini, A., Passoni, C., Belleri, A., Feroldi, F., Preti, M., Metelli, G., Riva, P., Giuriani, E., Plizzari, G. (2017). Combining seismic retrofit with energy refurbishment for the sustainable renovation of $\mathrm{RC}$ buildings: a proof of concept. European Journal of Environmental and Civil Engineering, 1-21.

Ministry Decree n.58 28/02/2017 Allegato A: linee guida per la classifcazione del rischio sismico delle costruzioni (in Italian). Italian Ministry of Infrastructures and Trasport, Italy.

Reinhart, C. F., and Davila, C. C. (2016). Urban building energy modeling-A review of a nascent field. Building and Environment, 97, 196-202.

Rossetto, T., Ioannou, I., \& Grant, D. N. (2013). Existing empirical fragility and vulnerability relationships: compendium and guide for selection. Pavia, Italy: GEM Foundation.

Simona, P. L., Spiru, P., \& Ion, I. V. (2017). Increasing the energy efficiency of buildings by thermal insulation. Energy Procedia, 128, 393-399.

Schwarz, J., Raschke, M., and Maiwald, H. (2006). Comparative seismic risk studies for German earthquake regions on the basis of the European macroseismic scale EMS-98. Natural hazards, 38(12), 259-282.

Tyagunov, S., Stempniewski, L., Grünthal, G., Wahlström, R., and Zschau, J. (2004). Vulnerability and risk assessment for earthquake prone cities. Proceeding of the 13th World Conference on Earthquake Engineering. Vancouver, Canada, 1-6 August 2004. 